\title{
Art, Complexity and Sustainability in the Anthropocene
}

\author{
A Case Study
}

BRIDIE LONIE

\begin{abstract}
This paper explains the thinking behind the exhibition The Complete Entanglement of Everything. The curators' premise was that, taken as whole, the exhibition would demonstrate the emergence of an understanding of the Anthropocene as it is playing out in Otepoti/Dunedin, New Zealand. The term "entanglement" was drawn from Donna Haraway's argument that the wicked problems of our present predicament will only be intelligible if we understand that categorical distinctions are a problem in themselves (Haraway 2016). While some works were didactic, others, less obvious, drew on the power that art has to enable conceptual understanding in such a way that it is experienced by each viewer as their own. The genre of conceptual art offers such experiences: theorist and art historian Gregory Minissale in The Psychology of Art characterizes it as a kind of bundling of affect, cognition and emotion that extends the development of understanding. (Minissale 2013). Curatorial projects can in themselves operate as conceptual art. The argument that culture is the fourth pillar of sustainability is strengthened when artworks are viewed as holding patterns, containers or vehicles, for emergent and complex scenarios. In that way, artworks can assist as much with acknowledging the forces -such as grief and the sense of impotence -that restrain us from action, as with gaining new approaches and new strength for engagement.
\end{abstract}

KEYWORDS: Art; Anthropocene; Psychology

\section{Introduction}

This presentation offers to the debate on education for sustainability an approach to art that is perhaps more friendly to other disciplines than art theory. The case study is an exhibition and symposium held in 2020 that I curated with Pam McKinlay at the Dunedin School of Art in Ötepoti/Dunedin. The programme of the exhibition, the catalogue, a Twitter archive and other documentation are available on our website. While the exhibition focused on the concept of the Anthropocene, many overlap with the Sustainable Development Goals.

While there is an abundance of philosophical theories that argue for art as a relational pursuit capable of participating in the transformation of societal attitudes, I found myself 
sometimes more enlightened by descriptions of the psychological apparatus that enables this. I found useful tools in Gregory Minissale's robust critique of the insistence on the sensory and the visual in most psychological models of art, particularly when confronted by contemporary art (Minissale 2013). Minissale argues that contemporary artworks are not simply sensory or even primarily visual experiences, but bundle cognition, affect and emotion, and elicit from their viewers the kind of thought" involved in creating relations and systems" (Minissale 2013,318 ). His approach offered a firm bedrock for an exploration of the ways that conceptual art has been used in the context of the transformation of planetary systems understood as the Anthropocene.

The Complete Entanglement of Everything juxtaposed the works of forty-nine mature and professional artists in five galleries formed within the Dunedin School of Art's buildings. The exhibition was accompanied by a two-day symposium, Mapping the Anthropocene in Otepoti/Dunedin: Climate change, community and research in the creative arts (Lonie and McKinlay, 2020). Both exhibition and symposium were designed to demonstrate the emergence of understandings of and responses to the qualities of the Anthropocene within the city, with the additional of other interested artists from around Aotearoa/New Zealand and in one case from Australia.

The symposium commenced with a welcome to the environment by Ron Bull of the iwi (tribal group) Kai Tahu, offering the point of view of the first peoples of this area of Aotea$\mathrm{roa} / \mathrm{New}$ Zealand. Aotearoa/New Zealand is a bicultural country and the structure of both the symposium and the exhibition sought to acknowledged tha though initial consultation and ongoing conversationst. Ōtepoti/Dunedin is a coastal city with increasingly frequent flooding in an area of high-density low decile housing, an area regarded by the rest of the country as New Zealand's postcard for climate change. The images show some of the consultation about the actual coastline, and an April Fool's Day joke in the local newspaper showing a marina amid the suburb, perhaps not so far from future options.

The city is also a thriving art centre with a city council arts and culture strategy (Ara Toi Ōtepoti) that includes all artforms, viewers and audience, culture and spirituality in its brief.(Dunedin City Council , 2017) The Dunedin School of Art at Otago Polytechnic also takes part in an annual art/science project with Otago University, in which scientists present their current research to a group of our postgraduates and alumni, who then pair up with with the scientists to create visual responses in an exhibition at the Otago Museum along with presentations by the researchers. Each year a particular group of researchers are focused. In 2021, the exhibition will focus on geophysical research. In 2019, the focus was on water, and several of the artists who showed in the exhibition under discussion showed the works again in the context of the Anthropocene.

The premise for the exhibition was our understanding of the Anthropocene as a wicked, complex network of present and emerging anthropogenic transformations of the ecosystems of the planet from which human values and decisions could not be separated. This understanding had grown as I researched my doctoral study, Closer relations, art, climate change, interdisciplinarity and the Anthropocene (Lonie 2018). This included a chapter on Lucy Lippard's curatorial project Weather Report, Art and Climate Change (Lippard 2007). Lippard argued that conceptual art would help viewers engage with the data required to understand climate change. Minissale extends the reach of conceptual art to include conceptual blending, long-term memory and relational knowledge, rational induction, analogical reasoning, proprioceptive and embodied knowledge, and emotional and sensory integration (Minissale 2013, $\mathrm{xvi)} \cdot$ His analysis provides an empirical model that might explain how artworks can perform the kind of integration of understanding required to enable people to acknowledge, come to 
terms with and negotiate the Anthropocene's characteristic and endemic wicked problems. These as we know involve the interpenetration of societal, geographical, ecological, and human, non-human, more than human, organic and inorganic interpenetrations of forms, a scenario expressed in my opinion best by Donna Haraway's notion of entanglement (Haraway 2016). Now a much-used term, her use of it stems from her initial interest in cybernetics, the construction of the notion of cybernetic organism, her understanding that the artforms of science fiction and fantasy had already reached these places, and her careful re-articulation of the power dynamics between different species.

Because art has become so implicated in the spectacle of economic growth on the one hand, and as the locus of individual self-expression on the other, its possibilities for processing important socio-ecological-political and economic transformations have been somewhat sidelined. Art is regarded as a nice-to-have, an accoutrement of the leisured classes, or the locus of specific cultural and identity expressions: all correct, but these focal points, however competitive they are in themselves, have not thus far included its function in the processing of the complexities thrown at us, the negotiation of competing discourses, and the strengthening of resilience. Yet engagement with art can be a powerful strategy for engaging with the uncertainties associated with complexity, as it has the capacity to bundle data with scenarios, affect with cognition and systems with specifics.

In addition, the experience of viewing art is socially naturalized as being personal, which means that viewers feel that they own their own responses. And, on the other hand, because exhibitions are public, viewing art is also regarded as collective, which enables viewers to feel part of a community whether through shared appreciation or alienation. Such projects require active viewing. They are not science communication, because they include quite explicitly the artist's own response to the data or information they convey.

The following examples may demonstrate the ways that artists have sought to bundle affect, cognition, and emotion to convey aspects of the Anthropocene, situated in the context of an art exhibition that, as a context, implies that the viewer will reflect on, respond to, and assess the value of the work in relation to their wider world view. In that sense, the exhibition itself may situate cognition as they build relationships between specific works and those that surround them, in association with the explicit themes of the exhibition (Minissale 2013, 251262). The Anthropocene is emergent both in its impacts and in the subjectivities it engenders: the descriptions below do not presume that they entirely describe the works nor the responses they elicit.

The exhibition opened in the context of the COVID-19 pandemic. At every entrance to the buildings visitors were asked to use hand sanitizers and sign in use QR codes. The white plastic sanitizer at our entrance was replaced by a black bottle with a green handle, and beside the QR code was a catalogue card with the words 'Andrew Last, Contact 2020; pounamu and plastic "absorbing mauri from all who touch the stone"'. We touch sanitizers constantly, and immediately wash away that contact, which may be contaminated. Yet the act of sharing the dispenser keeps us safe and links us as part of a site-specific, place-based community. Pounamu is a kind of jade, a precious cultural treasure or taonga and one that represents this country, in the complicated way that colonizers appropriate the cultures of their colonized peoples. The word 'mauri 'is used to indicate a life principle or force. This artwork connects the sense of touch, the affect of the collective fear and caution associated with COVID19, to make explicit the dialectical relationship between collectivity, community, and contamination. It also, as part of the act of entry into a space, reminds those who enter it that the environment is a bicultural one and that we stand on shared earth. The artist is a teacher in jewellery at the Dunedin School of Art who works closely with the Kaitohutohu Office, the polytechnic's 
Indigenous governance group in developing teaching projects based in traditional marae environments. Proprioceptive and embodied knowledge and emotional and sensory blending are elicited quietly in this work.

Heramaahina Eketone's work from a previous art/science project on water was placed on the wall outside the first gallery. Eketone's traditional carving is constructed of two hung together that refer to the city's harbour and the loss of its capacity to generate kai moana, or seafood, for the community. The whakatauki, or proverb Eketone brings to this narrative describes that loss as that of the behaviour of a careless child who has broken a precious tool. Eketone asks us to treasure even the broken tool, as we seek to renew the cleanliness of the waters. The work speaks to two communities: one who knows the narratives, and one for whom the narratives must be explained, as the knowledge that is generated will perform the remediative action of ensuring that the two communities of this bicultural country can understand each other, strengthened by the Indigenous voice. This work asks for conceptual blending, rational induction, and analogical reasoning.

Sculptor Michele Beevors constructs and knits life-size skeletons in response to the Sixth Extinction. She juxtaposed three works. Tales of Sorrow and Regret shows two child skeletons, their white bones knitted in patterns that show the bones' ridges and articulations, while on their backs these human children wear knitted versions of the consumer culture accoutrements that act as markers of identity through gender. Beside these on a construction made of waste materials sit tiny frogs. The third work is an emu, who stands on an artist's palette with measuring devices and wooden apples, referencing the development of the sciences of classification that in distinguishing between species fragmented our understanding of the integrated nature of the natural world. Beevors chooses to work with the non-iconic signifiers of extinction, though frogs have moved into that space. The viewer is asked to connect familiar consumer products with the act of extinction; the slow, careful, and patient act of knitting that we associate with nurture; and the production of waste and the plastics that poison our lands and waters. I think of each skeletal part as a tiny, knitted shroud. These works ask for conceptual blending, rational induction, analogical reasoning and draw on long-term memories as far apart as the embodied knowledge of the nurturing qualities of the knitted object and the association between apples and Newtonian physics.

Kristen O'Sullivan Peren's Master of Fine arts project The Rubbishlegium-Lost Paradise (2014) also calls on us to blend concepts, while experiencing an affective encounter with pulsing colours conveyed by a scattered collection of monitors in a darkened room. The title 'Rubbishlegium 'refers to the obvious digital rubbish represented both by the monitors and their association with digital waste in landfill, but it also refences the Florilegium of the collector and explorer Joseph Banks whose voyages led to the colonization of many of the lands washed by the Pacific Ocean. Banks was looking for possible commercially viable species, for markets, for lands to farm. Theorists propose many beginnings of the Anthropocene but in this country there is a distressingly close relationship between the eighteenth century's rapid industrialization and almost simultaneous destruction through colonization of the forested lands here and the rapid transformation of the country from slowly evolving ecosystem to industrialized agricultural landscape. Peren's concern is with the waste that contemporary life generates, and the wall text labels each digital artwork with its subject matter, such as the plastic generated by a family's Christmas dinner and the collected rubbish, sticky tape, wrappers, cellophane from a family of four people for one month. The works move in a dizzying cadence while the discarded monitors and their computing systems struggle to deal with the memory required by the images and must be re-booted. The work requires considerable input from its audience but the affect and the association with rubbish convey to me the nauseating

292

Art, Complexity and Sustainability in the Anthropocene

Futures of Education, Culture \& Nature - Learning to Become 
confusions of the Anthropocene. Close by, we placed Esta De Jong's tall mourning figure from the exhibition Becoming Darkness (2019) made of recycled black plastic, and Brendon Jon Philip's dark paintings on the cosmogonies of the Kaballah, in this instance Mem (2019), representing water. Philip writes: "This work is part of a metaphysical inquiry into cyclical models of creation, destruction and the phenomenological apprehension of the fluid and multiple play of existence". Our Anthropocene world entangles belief systems with the problematic of waste, the organic with the inorganic, and generates different versions of the numinous in what Timothy Morton and others call dark ecologies (Morton, 2016).

In a work that might speak more to European audiences, though tepotii/Dunedin is a refugee settlement destrination, contemporary jeweller Johanna Zellmer's explorations of the developing intricacies of identity and migration articulate the ways that digital identity tagging engages economic, political, and biochemical epistemologies. Zellmer's heated and burnt plastic DNA test strips and re-assembled identity cards are spiky with aggression, melted into an inextricable blend of the organic and the inorganic, yet, exhibited in museum cases, carry the attributes of an apparently empirical and disassociated science.

Collectivity may be experienced in shared game playing. During the exhibition Ruth Evan's Master of Fine arts project Go Mine! (2019) was played by groups who were guided through the rules of the game to over-ride environmental protection legislation, thus gaining the skills to understand the "other side" of the power equation. Here knowledge was embedded in association with the pleasure and and adrenalin typical of the experience of playing competitively. This was a work that appealed to young people; it has been used by high school activists as a kind of training.

In its totality, the exhibition sought to elicit the combination of cognition and sensation that is the primary characteristic of the artwork, to assist viewers to process and internalize the complex interdisciplinary understandings that underpin the concept of the Anthropocene and its cognates. An empathic space is offered: the viewer is held for a period within the act of making sense, and consequently owns the sense they have made.

\section{Literature}

Dunedin City Council, Ara Toi, The Arts and Culture Strategy https://www.dunedin.govt.nz/council/strategic-framework/ara-toi-the-arts-and-culture-strategy

Donna J. Haraway, "Staying with the Trouble: Anthropocene, Capitalocene, Chthulucene", in Jason W. Moore (editor) Anthropocene or Capitalocene? Nature, History and the Crisis of Capitalism Oakland, CA: PM Press (2016) 34-76 The literature on the Anthropocene is extensive, but Jason W. Moore's selection of competing positions provided a useful context for the project.

Lucy Lippard, Stephanie Smith and Andrew Revkin, Weather Report, Art and Climate Change, Boulder Colorado: Boulder Museum of Contemporary Art, 2007.

Bridie Lonie, The Complete Entanglement of Everything (catalogue essay) https://issuu.com/dunedinschoolofart/docs/the complete entanglement of everything exhibition

Bridie Lonie and Pam McKinlay, Mapping the Anthropocene in Otepoti/Dunedin, Climate Change, community and research in the visual arts, (programme and abstracts) https://www.op.ac.nz/assets/Mapping-the-Anthropocene-2020-ABSTRACTS-FINAL-SEP2020.pdf and https://issuu.com/dunedinschoolofart/docs/the complete entanglement of everything exhibition 
Pam McKinlay and Jenny Rock, , Art and Water, curated exhibition and catalogue: https://issuu.com/dunedinschoolofart/docs/art_water_exhibition_catalogue_2019

Gregory Minissale, The Psychology of Contemporary Art, New York: Cambridge University Press, 2013

Timothy Morton, Dark Ecology, For a logic of future co-existence, New York: Columbia University Press, 2016. 